\title{
Analyzing Competencies of Indian Health Care Leaders: Way Forward for Next Generation
}

\author{
${ }^{1}$ SK Patnaik, ${ }^{2}$ Shakti K Gupta, ${ }^{3}$ S Kant, ${ }^{4}$ R Pillay
}

\begin{abstract}
Introduction: Indian health care is experiencing a paradigm shift in terms of requirement of resources and changing demographic patterns. The customer-oriented and quality-conscious competitive environment has intensified the need for health care organizations to attain higher levels of organizational performance. Competencies of health care leaders play a pivotal role in deciding the organizations' way forward and competencies are the cornerstone of organizational performance and quality standards. A cross-sectional study of select health care leaders of India was done from various hospitals and other health delivery agencies to identify and analyze the gaps in competencies.
\end{abstract}

Materials and methods: A cross-sectional study was planned amidst health care leaders of India so as to assess their leadership competencies. Health care leaders of India were identified after focused group discussion and senior health care leaders, such as directors, deans, CEOs, and principals were shortlisted for this study. Two structured questionnaires were administered to health care leaders of various hospitals in India. The ratings in the questionnaire were on a Likert scale ranging from very poor to excellent. Respondents were asked to self-evaluate various competencies and the same were analyzed using Statistical Package for the Social Sciences statistical software. Interpretation of results of data analysis was done.

Results: A total of 300 questionnaires were sent of which 106 questionnaires were completed and returned by select health care leaders. About 78 were doctors and 28 were nursing executives. The study has been able to identify deficiencies in the perceived "existing competency" and "required competency" levels in the selected competencies.

Conclusion: The findings of this study suggest that there is deficiency in perceived "existing competency" and "required competency" levels in the selected competencies of health care leaders. Indian health care leaders are operating at operational levels and have not graded themselves highly in transformational roles. There is a need for training to bridge the competency gap of Indian health care leaders.

\footnotetext{
${ }^{1} \mathrm{MO}(\mathrm{HS}),{ }^{2}$ Medical Superintendent, ${ }^{3}$ Professor and Head ${ }^{4}$ Professor

${ }^{1}$ OIC Pay cell, o/o DGAFMS, New Delhi, India

${ }^{2}$ Dr. R. P. Centre for Ophthalmic Sciences, All India Institute of Medical Sciences, New Delhi, India

${ }^{3}$ Department of Hospital Administration, Armed Forces Medical College, Pune, Maharashtra, India

${ }^{4}$ Healthcare Innovation, University of Alabama at Birmingham USA

Corresponding Author: SK Patnaik, MO (HS), OIC Pay cell o/o DGAFMS, New Delhi, India, e-mail: patnaik.saroj@ gmail.com
}

Keywords: Accountability, Competencies, Health care, Health leaders, Medical technology, Process management, Strategic orientation.

How to cite this article: Patnaik SK, Gupta SK, Kant S, Pillay R. Analyzing Competencies of Indian Health Care Leaders: Way Forward for Next Generation. Int J Res Foundation Hosp Healthc Adm 2017;5(1):47-53.

\section{Source of support: Nil}

Conflict of interest: None

\section{INTRODUCTION}

The health sector in India is undergoing a paradigm shift. Medical tourism, public-private partnership, medical technology, and mobile outreach services are some of the factors responsible for changing the health care delivery facet. In the metamorphosing environment, Indian health care leaders have to face fresh challenges everyday. Thus, it is important to assess their leadership competencies, which can help Indian health care leaders attain their objective. These objectives, when attained, will help India propel into a country where wellness will be the guiding factor and the health sector will reach out to the deep interiors of our country. To achieve the various health care goals and plans as designed by the leaders, their role in redefining delivery is of utmost importance. All managers, irrespective of where or what they manage, perform four generic tasks. These include planning, organizing, leading, and controlling. ${ }^{11}$ Planning involves defining goals and mapping out ways to reach them; organizing entails arranging and coordinating human, material, and information resources aimed at achieving desired goals; leading involves motivating others to achieve organizational goals; and controlling involves measuring performance and monitoring progress relative to objectives. ${ }^{1}$

There are three well-known styles of leadership: Transformational leadership, transactional, and laissezfaire.

Transformational leaders encourage subordinates to adopt the organizational vision as their own, through inspiration, thus adopting a long-term perspective and focus on future needs. Transformational leaders tend to have a holistic perspective of organizational factors.

Transactional leaders identify and clarify job tasks for their subordinates and communicate how successful execution of those tasks will lead to receipt of desirable 


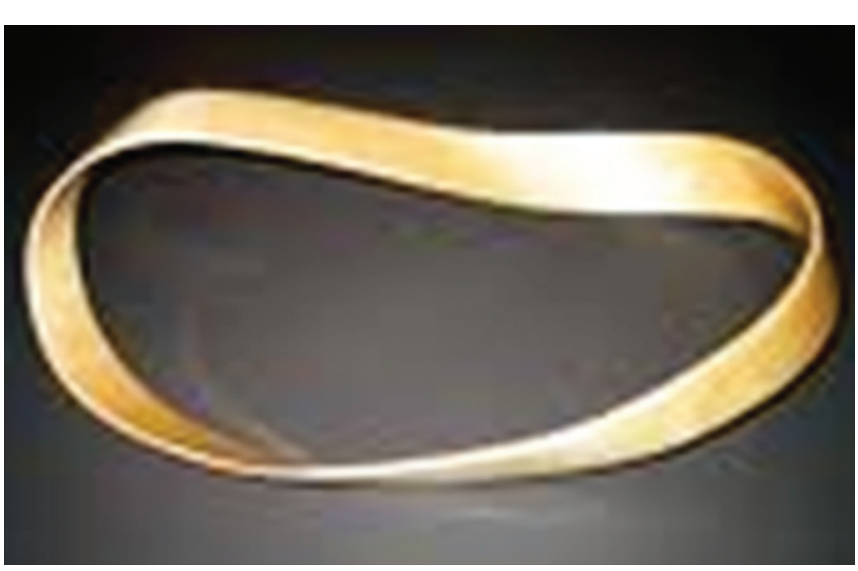

Fig. 1: Möbius strip

job rewards (Bass). According to Avolio et al, ${ }^{2}$ a transactional leader determines and defines goals for their subordinates and suggests how to execute tasks.

Laissez-faire leaders abandon their responsibility, leaving their subordinates to work relatively on their own and avoid making decisions.

It is clear from the definitions that leadership can be viewed in terms of multiple perspectives, and that it can be represented as existing as an act, behavior, or process.

Leadership is a social influence process shared among all members in a group. Leadership is not restricted to the influence exerted by someone in a particular position or role; followers are part of the leadership process. In recent years, both practitioners and scholars have emphasized the relatedness of leadership and followership.

Thus the question "what is leadership" cannot be separated from "what is followership?" There is no simple line dividing them, they merge. The relationship between leadership and followership can be represented by borrowing a concept from topographical mathematics: The Möbius strip (Fig. 1).

Möbius strip is a strip of paper folded and connected in a manner that it proves to have only one side. Thus, leadership and followership written on either side merge into one another and become indistinguishable.

\section{LEADER-FOLLOWER RELATIONSHIP}

Fred Fiedler was perhaps the first researcher who formally recognized the importance of leader, follower, and situation in the leadership process. Leadership is an interaction of three elements - the leader, the follower, the situation (Graph 1).

Thus leadership is $\mathrm{L}=\mathrm{f}(\mathrm{l}, \mathrm{f}, \mathrm{s})^{3}$

It is important to understand here that when this definition refers to leaders and followers, one should not assume that it refers to only a hierarchical relationship. Any time an individual is attempting to influence the behavior of someone else, that individual is the potential

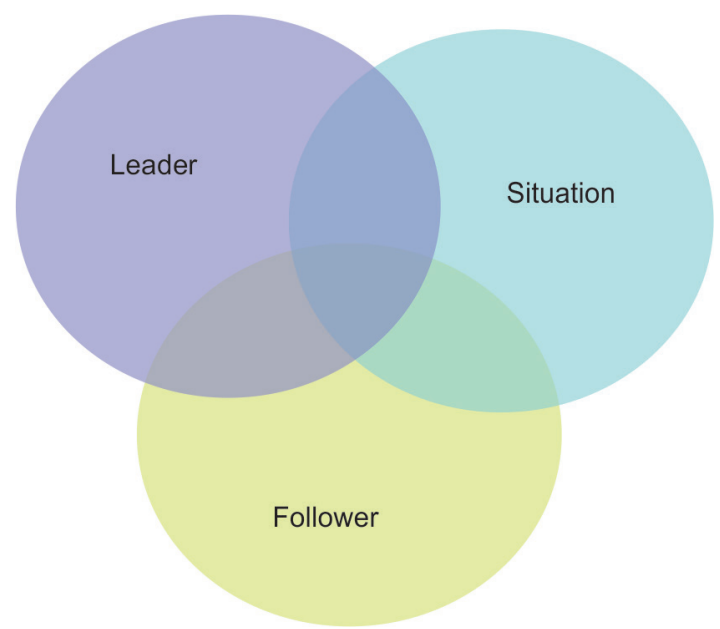

Graph 1: Leader-follower relationship

leader and the person subject to the influence attempt is the potential follower. ${ }^{4}$

Leadership is the result of a complex set of interactions among leaders, followers, and situations. An example of one such interaction between leaders and followers is evident in what has been called in-groups and outgroups. Sometimes, there is a high degree of mutual influence and attraction between the leader and few subordinates, these subordinates belong to the in-group. Other subordinates belong to the out-group. Leader member exchange theory describes these two kinds of relationships and how they affect the types of power and influence tactics leaders use. Followers' expectations, personality trait, maturity levels, levels of competence, and motivation affect the leadership process. The situation is the third critical part of the leadership equation. Concept of leadership and their interaction with follower are highly dependent on situations. ${ }^{5}$

\section{Competency}

Competency is defined as the minimum standards required to perform a job. A competent individual has the requisite skills and abilities to perform a job satisfactorily. Competency assessment ensures that every employee performs at least at minimal acceptable level. Competency assessment also gives us an insight into why some perform exceedingly well whereas others fail under similar situations.

\section{WHY ARE COMPETENCIES IMPORTANT?}

Competencies ${ }^{6}$ are a critical lever to produce leadership brand within an organization for at least five reasons as they:

1. Guide direction

2. Are measurable

3. Can be learnt

4. Can distinguish and differentiate the organization

5. Can help integrate management practices. 
It is essential to endow health care leaders in India with requisite competencies to handle situations arising out of the changing scenario of health care sector. Health leaders are especially challenged to create work climates that motivate high-quality, patient-centered care and retain high-demand talent in a very competitive marketplace. ${ }^{7}$

Now the cause of concern is to find if health care leaders of India at various levels of management have the required skills to lead their teams in trying times. It is imperative to assess the presence of critical competencies of health care leaders, which they can gainfully utilize for optimal health care delivery. Competencies of health care leaders in India need to be identified without which the process of leading and ultimate vision of realizing health care goals may be compromised.

\section{MATERIALS AND METHODS}

The National Centre for Health Care Leadership (NCHL) (2006) defined three domains-transformation (strategic), execution (organizing and controlling), and people (leadership)—comprising 26 competencies which encapsulates health management today. This study utilized the NCHL model to generate a questionnaire that aimed to assess the perceived and the required skills and competencies of Indian health care leaders so as to analyze the gaps and the need for augmenting specific skills.

Two questionnaires, scaled on Likert scale, were framed out of selected competencies from various health care models and distributed amidst the selected sample of health care leaders who were doctors and nursing executives.

The first questionnaire elicited response to Please rate your level of competency.

The second questionnaire elicited response to How important do you think the following competencies are

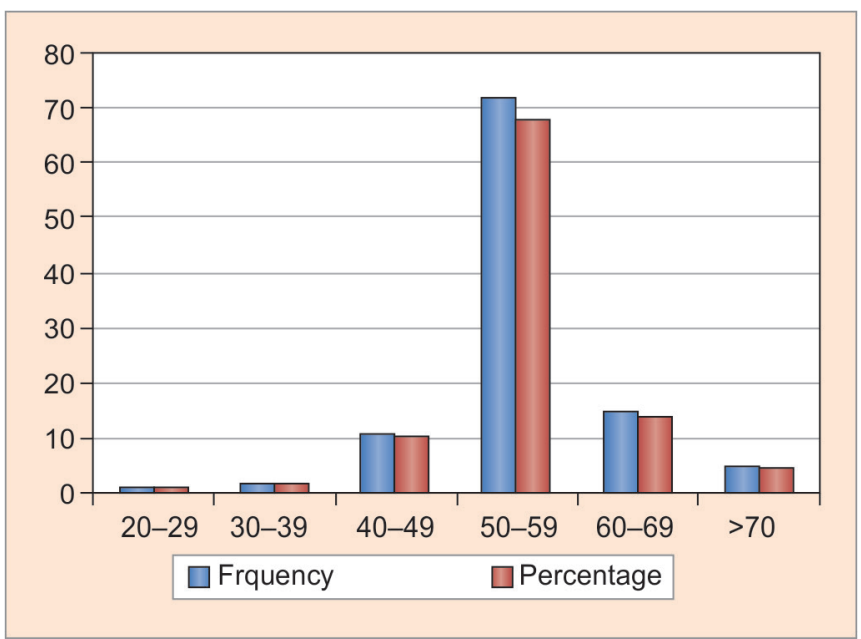

Graph 2: Age distribution for you to perform your duties efficiently and effectively?

The first questionnaire elicited the perceived level of the individual health care leader's competencies and the second questionnaire elicited the perceived need for same competencies for effective execution of their task.

Structured questions were quantified and were tabulated on an Excel sheet. The data collected from both questionnaires were tabulated in various combinations and were analyzed using Statistical Package for the Social Sciences version 15. Data were described with mean, standard deviation (SD), and frequency with percentage. The data were subjected to paired t-test and independent t-test for evaluation. Student's t-tests were carried out to measure the significance of the difference between the means of self-assessed proficiency levels and perceived importance levels. The scales of each competency level were administered reliability tests in form of Cronbach's alpha and tested. These were then subjected to analysis and further inferences were drawn. Inferences were drawn about health care leaders' competencies from the questionnaires. Evaluation of questionnaires was also drawn to analyze competencies between trained, untrained health care leaders, and public, private sector health care leaders.

\section{RESULTS}

\section{Respondent Data}

Respondent data revealed that most health care leaders are in the age group of 50 to 59 (Graph 2 and Table 1). Males outnumber the females in gender distribution (Graph 3). A total of 82 respondents were in their current position for less than 10 years (79.61\%). A total of 45 $(43.27 \%)$ respondents were in management position for less than 10 years. A total of $93(87.74 \%)$ respondents were specialists and $13(12.26 \%)$ were nonspecialists. This is evident of the fact that the specialists take on the

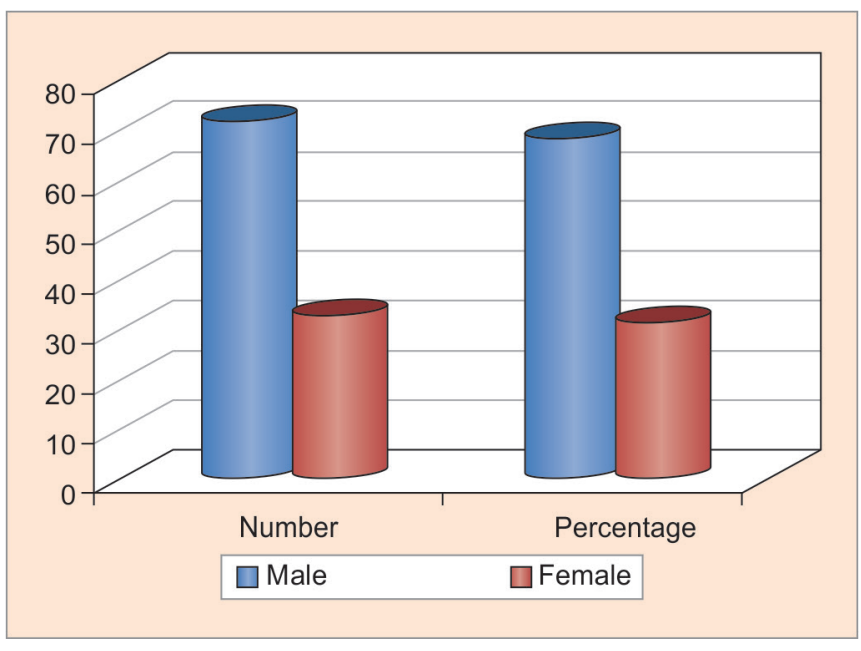

Graph 3: Gender distribution 


\begin{tabular}{|c|c|c|c|c|c|}
\hline \multicolumn{3}{|c|}{ Table 1: Respondent profile analysis } & & Frequency & Percentage \\
\hline & Frequency & Percentage & Hospital size & & \\
\hline Age in years & & & Less than 100 & 21 & 20 \\
\hline $20-29$ & 1 & 0.94 & $101-300$ & 17 & 16.19 \\
\hline 30-39 & 2 & 1.89 & $301-500$ & 7 & 6.67 \\
\hline $40-49$ & 11 & 10.38 & More than 500 & 60 & 57.14 \\
\hline $50-59$ & 72 & 67.92 & Number of employees & & \\
\hline $60-69$ & 15 & 14.15 & Less than 100 & 18 & 17.14 \\
\hline 70 more & 5 & 4.72 & $101-500$ & 16 & 15.24 \\
\hline Sex & & & $501-1000$ & 21 & 20.00 \\
\hline Male & 72 & 68.57 & More than 1000 & 50 & 47.62 \\
\hline
\end{tabular}

\section{Female}

Clinical experience (years)

Less than 10

31.43

10-20

21-30

$31-40$

More than 40

Years in management position

Less than 10

10-20

21-30

31-40

More than 40

Years in current position

Less than 10

10-20

21-30

31-40

More than 40

Primary academic qualification

Medical

Nursing

Specialization

Specialists

Nonspecialists

Type of specialization

MCh, DM, PhD

MD, MS, MHA

Nursing $P G$

Diploma

Others

Exposure to training in health administration

Trained

Untrained

18

Formal training

Degree

Certificate

Others

Informal training

Mentored

Coached

In-house programme

Job shadowed

Others

Sector

Public

Private
23.81

31.43

25.71

17.14

1.90

43.27

34.62

13.46

7.69

0.96

79.61

15.53

3.88

0.97

$-$

(Cont'd...)

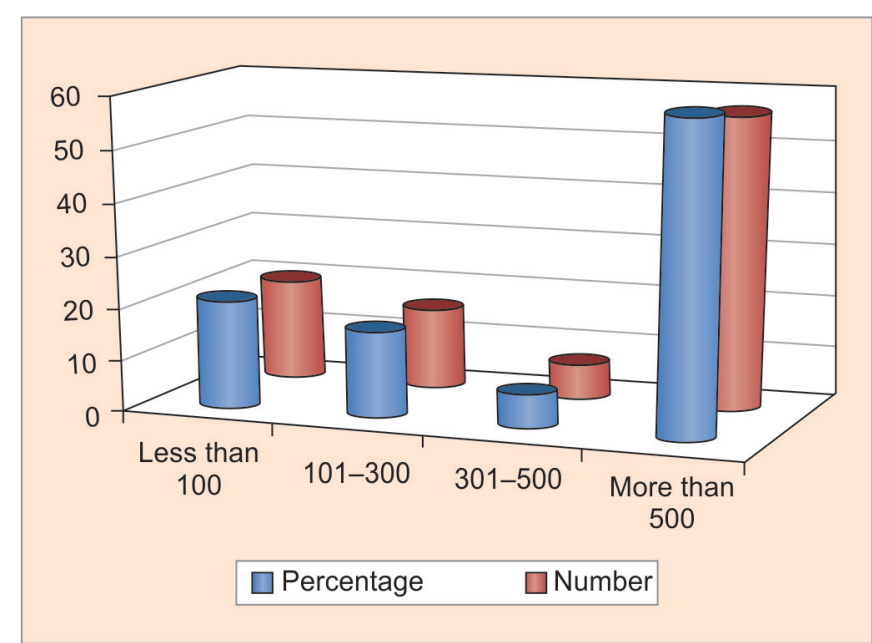

Graph 4: Size of hospitals in relation to hospital beds

administrative responsibilities in the later part of their career. A total of $88(83.02 \%)$ respondents had training in health and nursing administration. Formal training in the form of awarded degree was received by $39(38.24 \%)$ and certificate training was received by $31(30.39 \%)$.The number of respondents from public sector were 81 (76.2\%) and from private sector were $25(23.58 \%)$. A total of $60(57.14 \%)$ respondents were from hospitals, which are 500 bedded or more (Graph 4).

\section{Evaluation of Competencies of Health Care Leaders}

Analysis of competencies of 106 health leaders was done. The statistical details are shown in Table 2. The questionnaire had more than 7 pages, which made it a long questionnaire. As per a study done by Iglesias and Trogreson in 2000, ${ }^{8}$ the response rate of a long questionnaire is $40.5 \%$. According to a study done by Trogreson, ${ }^{9}$ the response rate of $40 \%$ is modest, it confirms the views of Hill and Winfrey that it is increasingly difficult to achieve desirable response rates in surveys of physicians. It is also consistent with rates commonly obtained among elite professionals. ${ }^{10}$ The scales of the competencies were subjected to Cronbach's alpha, and it has been found that in both the questionnaires, the Cronbach's alpha is more than 0.6 for all competencies. 
Analyzing Competencies of Indian Health Care Leaders: Way Forward for Next Generation

Table 2: Competencies of health care leaders

\begin{tabular}{|c|c|c|c|}
\hline Competency $n=106$, health leaders & Q1 mean $\pm S D$ & Q2 mean $\pm S D$ & $p$-value* \\
\hline Accountability & $17.91 \pm 3.65$ & $18.87 \pm 3.80$ & 0.001 \\
\hline Achievement orientation & $21.92 \pm 4.099$ & $22.88 \pm 4.56$ & 0.005 \\
\hline Analytical thinking & $14.47 \pm 2.74$ & $14.66 \pm 3.990$ & 0.610 \\
\hline Change leadership & $21.76 \pm 4.074$ & $22.19 \pm 4.378$ & 0.146 \\
\hline Collaboration & $19.07 \pm 3.84$ & $19.39 \pm 3.883$ & 0.198 \\
\hline Communication skills & $14.96 \pm 3.123$ & $14.79 \pm 3.060$ & 0.463 \\
\hline Community orientation & $21.91 \pm 4.712$ & $22.42 \pm 4.30$ & 0.104 \\
\hline Financial skills & $16.10 \pm 4.021$ & $16.94 \pm 4.10$ & 0.018 \\
\hline Human resources management & $13.06 \pm 2.70$ & $3.71 \pm 2.50$ & 0.013 \\
\hline Impact and influence & $19.60 \pm 3.84$ & $19.87 \pm 3.72$ & 0.383 \\
\hline Information seeking & $18.07 \pm 3.45$ & $18.68 \pm 3.62$ & 0.020 \\
\hline Information technology management & $14.30 \pm 2.91$ & $14.59 \pm 2.84$ & 0.194 \\
\hline Initiative & $17.77 \pm 3.7218$ & $13 \pm 3.56$ & 0.168 \\
\hline Innovative thinking & $18.12 \pm 3.35$ & $18.47 \pm 3.57$ & 0.168 \\
\hline Interpersonal understanding & $18.33 \pm 3.64$ & $18.35 \pm 3.41$ & 0.938 \\
\hline Organizational awareness & $17.08 \pm 3.63$ & $17.59 \pm 3.61$ & 0.069 \\
\hline Performance measurement & $10.19 \pm 2.24$ & $10.89 \pm 2.33$ & 0.001 \\
\hline Process management & $13.75 \pm 3.17$ & $14.58 \pm 3.008$ & 0.001 \\
\hline Professionalism & $15.11 \pm 3.096$ & $15.21 \pm 2.96$ & 0.668 \\
\hline Project management & $10.75 \pm 2.272$ & $10.75 \pm 2.441$ & 0.959 \\
\hline Relationship building & $17.78 \pm 3.77$ & $18.45 \pm 3.82$ & 0.019 \\
\hline Self-confidence & $19.03 \pm 3.74$ & $19.19 \pm 3.772$ & 0.549 \\
\hline Self-development & $14.76 \pm 2.76$ & $15.13 \pm 3.16$ & 0.084 \\
\hline Strategic orientation & $13.42 \pm 2.91$ & $14.06 \pm 3.02$ & 0.008 \\
\hline Talent development & $21.92 \pm 4.60$ & $22.29 \pm 4.28$ & 0.241 \\
\hline Team leadership & $22.89 \pm 4.92$ & $23.15 \pm 4.94$ & 0.395 \\
\hline
\end{tabular}

*Paired t-test

In most of the competencies, it is more than 0.8 , which means that the scales are reliable. The study suggests that there is a definite gap between the perceived selfcompetency level and the perceived required competency for executing the task. There is a requirement of more training for health care leaders in all the competencies, so that their competency level is augmented.

\section{Statistically Significant Competencies}

Of the 26 competencies, there are 8 competencies that are statistically significant. Indian health leaders require training in all the 26 competencies that have been studied in this research work. It is evident that the perceived level of competency is definitely less than perceived required level of competency.

The statistically significant competencies are:

- Financial skills

- Human resource management

- Performance measurement

- Process management

- Strategic orientation

- Accountability

- Achievement orientation

- Relationship building.

The first five competencies from the above are technical competencies, which can be augmented by training.
The competencies have been grouped as technical competencies and nontechnical competencies. Technical competencies are defined as those competencies in which training can be imparted to augment existing levels. Nontechnical competencies have to be acquired and can be learnt by behavioral modifications.

\section{TECHNICAL COMPETENCIES}

\section{Financial Skills}

Financial skills means the ability to understand and explain financial and accounting information, prepare and manage budgets, and make sound long-term investment decisions. As per a study done by Schultz and Pal, ${ }^{11}$ it has been found that most health care CEOs need financial skills. Indian health care leaders in private sector have shown significant interest and expressed the need for better augmentation of this competency.

\section{Human Resource Management}

Human resource management is the ability to implement staff development and other management practices that represent contemporary best practices, comply with legal and regulatory requirements, and optimize the performance of the workforce, including performance assessments, alternative compensation, and benefit methods, 
and the alignment of human resource practices and processes to meet the strategic goals of the organization. As per a study done by Greene, ${ }^{12}$ it is found that leaders make people around them to succeed. They recruit people, develop people, and get rid of inappropriate people. The high self-assessment of people management competencies is found to be consistently important for senior leaders across general management. ${ }^{13}$

\section{Performance Management}

Performance management is the ability to understand and use statistical and financial methods and metrics to set goals and measure clinical as well as organizational performance; commitment to and employment of evidence-based techniques. Schultz aptly notes that many elements of quality leadership have appeared separately in fads that swept through business schools and organizations, such that many are unfamiliar with a comprehensive approach to performance improvement, which has been termed as a "new way of doing business." 11

\section{Process Management}

Process management means the ability to analyze and design or improve an organizational process, including incorporating the principles of quality management as well as customer satisfaction.

Indian health care leaders can augment this competency by identifying key decision points, understanding customer service and satisfaction drivers, and continuum of care across different delivery sites (e.g., outpatient, acute care, specialty clinic), etc., and by organizing structure to design and improve performance. Clinical process redesign means the effective design of the continuum of care to satisfy customers, improve patient outcomes, maximize efficiencies, and improve organizational climate. Given the long tradition of research-based care, the physician leaders showed interest in using research evidence to guide care decisions and develop protocols. ${ }^{14}$

\section{Strategic Orientation}

Strategic orientation is the ability to consider the business, demographic, ethnocultural, political, and regulatory implications of decisions and develop strategies that continually improve the long-term success and viability of the organization. Health care leaders can do strategic planning by assessments of internal and external environments, doing a strengths, weaknesses, opportunities, and threats analysis, development of strategic initiatives, and periodic evaluation of results to check progress and verify final outcomes. ${ }^{15}$ In health care management literature, little attention is paid to the quality and impact of strategic decisions made by top executives. ${ }^{11}$ This lack of research is of concern given the unique performance criteria of health care organizations.

\section{NONTECHNICAL COMPETENCIES}

\section{Accountability}

The ability to hold people accountable to standards of performance or ensure compliance using the power of one's position or force of personality appropriately and effectively, with the long-term good of the organization in mind. The way in which accountability is created, negotiated, communicated, and evaluated lies at the heart of organizational operations.

\section{Achievement Orientation}

It is a concern for surpassing a standard of excellence. The standard may be one's own past performance (striving for improvement); an objective measure (results orientation); outperforming others (competitiveness); challenging goals; or something that has not been done previously (innovation).

Indian health care leaders have a strong will of achieving and delivering expected results in line with job requirements. Individuals with higher achievement orientation scores set higher goals for themselves and put in necessary time and effort in that process. Studies prove that all things being equal, people with higher levels of achievement orientation are more likely to do better in school, pursue postgraduate courses, and get promoted more quickly and earn higher salaries. ${ }^{16}$ Atkinson ${ }^{17}$ proposed that an individual's tendency to exert effort toward accomplishment depended partly on the strength of his or her motive to achieve success or achievement orientation.

\section{Relationship Building}

Relationship building is the ability to establish, build, and sustain professional contacts for the purpose of building networks of people with similar goals and that support similar interests. Highly effective leaders are very selective with whom they develop informal power relationship. They seek out individuals most likely to be helpful to them in the future. In every organization, an informal network, frequently called the shadow system, exists and often works better than formal systems of meetings and councils. ${ }^{18}$ Everything is built on good and sustainable relationships. The leader continually tests, challenges, and extends personal and collective relationships with stakeholders throughout the process of changing behavior. When things get tough or stuck, the only resource may be the personal relationship. ${ }^{19}$ Thus, Indian health care leaders can develop informal 


\begin{tabular}{llll}
\hline \multicolumn{3}{c}{ Table 3: Domain analysis } \\
\hline \multirow{3}{*}{ Domain } & Question 1 & Question 2 & p-value \\
\cline { 2 - 4 } & Mean $\pm S D$ & Mean $\pm S D$ & (paired t-test) \\
\hline Transformation & $2.91 \pm 0.52$ & $3.01 \pm 0.55$ & 0.012 \\
People & $3.66 \pm 0.66$ & $3.73 \pm 0.68$ & 0.108 \\
Execution & $3.65 \pm 0.63$ & $3.64 \pm 0.65$ & 0.028 \\
\hline
\end{tabular}

contacts, sustain formal contacts, and establish important relationships with key leaders.

\section{DOMAIN ANALYSIS}

Domain analysis of three domains, namely transformation, people, and execution was done with the help of both the questionnaires (Table 3). Domain analysis was done by taking the mean of various competencies of each domain. A paired t-test was done to assess the statistical significance. The results are as follows (Table 3):

- In Indian health care leaders, the perceived competency level of transformation domain is least compared with other two domains. Any leadership program, i.e., to be planned should concentrate on this domain, so as to improve the competency levels of Indian health care leaders.

- In Indian health care leaders, the perceived competencies level of the people domain and execution domain are almost at par and Indian health care leaders need more training to bridge the evident competencies gap.

- Both the transformation and execution domains are statistically significant, i.e., the p value is less than 0.05 , which means that the findings are not by chance.

In the analysis of domains, it was found that the transformation domain, which should be maximum in senior leaders of health sector is found wanting. It appears that the Indian health care leaders are working at operational level and decentralization of decision making is not practiced much. A training program focusing on the transformational skills will benefit the Indian health care leaders.

\section{CONCLUSION}

The study has found deficiencies in the perceived "existing competency" and "required competency" levels in all the 25 competencies except communication skills of health care leaders. The study reveals a scope for leadership training in the health sector. The areas in which lack of knowledge or skills was most significant were identified. This will help us identify the competencies required for various levels of leadership position.

\section{REFERENCES}

1. Pillay R. The skills gap in hospital management: a comparative analysis of hospital managers in the public and private sectors in South Africa. J Health Manage 2010 Mar;12(1): $1-18$.

2. Avolio B J, Waldman D A, Yammarino F J(1991). Leading in the 1990s: The four is of transformational leadership. J of European Industrial Training, 14(4):9-16

3. Paul, H.; Blanchard, KH.; Johnson, DE. Management of organizational behaviour. 9th ed. New Delhi: PHI publishing private limited; 2009. p. 62.

4. Paul, H.; Blanchard, KH.; Johnson, DE. Management of organizational behavior. 9th ed. New Delhi: PHI publishing private limited; 2009. p. 63.

8. Hughes, RL.; Ginnet, RC.; Curphy, GJ. Leadership: leadership is everyone's business. 6th ed. New Delhi: Tata Mc-Graw Hill Publishing Company Limited; 2008. p. 27.

6. Intagliata J, Ulrich D, Smallwood N. Leveraging leadership competencies to produce leadership brand: creating distinctiveness by focusing on strategy and results. Hum Resour Planning 2000 Winter;23(4):12-23.

7. National Centre for Healthcare Leadership Health Leadership Competency model, Version 2.0. p. 3.

8. Iglesias and Trogreson. Does length of questionnaire matter? A randomised trial of response rates to a mailed questionnaire. J Health Serv Res Policy. 2000 Oct;5(4):219-221.

9. Trogreson D. Increasing response rate to postal questionnaire. [cited 2010 Jul 14]. Available from: http://www-users.york. ac.uk/ mb55/msc/clinimet/week6/response_text.pdf.

10. Pillay R. Work satisfaction of medical doctors in the South African private health sector. J Health Organ Manage 2008 Feb;22(3):254-268.

11. Schultz FC, Pal S. Who should lead a healthcare organization: MDs Or MBAs? J Healthc Manag 2004 Mar-Apr;49(2):103-116

12. Greene RT. 64 Functions ( $\& 4$ dimensions) of leadership and management. J Policy Stud 2009 Jul;32:93-120.

13. Lussier, RN. Management fundamentals: concepts, applications, skills development. Mason $(\mathrm{OH})$ : Thomson SouthWestern; 2006.

14. Barker, AM.; Sullivan, DT.; Emery, JM. Leadership competencies for clinical managers. Canada: Joness and Bartlett publishers; 2006. p. 175.

15. Barker, AM.; Sullivan, DT.; Emery, JM. Leadership competencies for clinical managers. Canada: Joness and Bartlett publishers; 2006. p. 107.

16. Hughes, RL.; Ginnet, RC.; Curphy, GJ. Leadership: leadership is everyone's business. 6th ed. New Delhi: Tata Mc-Graw Hill Publishing Company Limited; 2008. p. 300.

17. Atkinson JW. Motivational determinants of risk taking behavior. Psychol Rev 1957 Nov;64Part 1(6):359-372.

18. Barker, AM.; Sullivan, DT.; Emery, JM. Leadership competencies for clinical managers. Canada: Joness and Bartlett publishers; 2006. p. 65.

19. Grady, TP.; Malloch, K. Quantum leadership. 2nd ed. Canada: Jones and Bartlett publishers; 2007. p.359. 